\title{
Crisis del sistema capitalista mundial: paradojas y respuestas
}

\author{
Humberto Márquez Covarrubias \\ Universidad Autónoma de Zacatecas, Zacatecas, México. Email: \\ hmarquez@estudiosdeldesarrollo.net
}

Resumen: La comprensión de la actual crisis del sistema capitalista mundial reviste una gran complejidad analítica: concita siete explicaciones teóricas canalizadas por tres vertientes paradigmáticas, expresa diez dimensiones críticas, afronta cuatro paradojas sintomáticas y suscita seis respuestas políticamente diferenciadas. Además de examinar el intrincado debate, este artículo analiza críticamente la crisis como un problema de carácter estructural, sistémico y civilizatorio. En primera instancia, esta es una crisis de valorización que entraña una espiral de sobreacumulación, la caída de la tasa de ganancia y la ruptura de las dinámicas de acumulación; pero en última instancia significa una crisis civilizatoria. La acumulación mundial centralizada, comandada por el capital transnacional y basada en la explotación del trabajo barato, devastación ambiental y financiarización muestra sus verdaderos límites. Empero, el gran capital pretende restaurar el proceso de concentración de capital, poder, riqueza y conocimiento, sin importar que la vida humana y el metabolismo social estén amenazados de múltiples formas.

Palabras clave: crisis, crisis civilizatoria, desarrollo desigual, acumulación mundial centralizada, metabolismo social

\section{Crisis of capitalist world system: paradoxes and answers}

\begin{abstract}
The understanding of the present crisis of world capitalist system is of great analytical complexity: it attracts seven theoretical explanations channeled through three paradigmatic strands, expresses ten critic dimensions, faces four symptomatic paradoxes and raises six politically differentiated responses. In addition to examining the intricate debate, this article critically examines the crisis as a structural, systemic and civilizatory problem. In first instance, this is a crisis of valorization which involves a spiral of over-accumulation, the falling rate of profit and the breakdown of the dynamics of accumulation; but ultimately it represents a crisis of civilization. The centralized global accumulation, led by transnational capital and based on the exploitation of cheap labor, environmental devastation and financialization, shows its true limits. Yet big business seeks to restore the process of capital concentration, power, wealth and knowledge, disregarding that human life and social metabolism are threatened in many ways.

Key words: crisis, civilizatory crisis, uneven development, centralized global accumulation, social metabolism
\end{abstract}

\section{Crise do sistema capitalista mundial paradoxos e respostas}

Resumo: A compreensão da atual crise do sistema capitalista mundial é de 
grande complexidade analítica, atrai sete explicações teóricas canalizada através de três vertentes dez dimensões paradigmática expressa a crítica, enfrenta quatro paradoxos sintomático e invoca seis diferentes respostas políticas. Além de examinar a polêmica, este artigo analisa criticamente a crise como um problema estrutural, sistêmica e de civilização. Em primeira instância, esta é uma crise de recuperação envolveu numa espiral de super-acumulação, a queda da taxa de lucro eo colapso da dinâmica de acumulação, mas em última análise, significa uma crise de civilização. $\mathrm{O}$ acúmulo centralizado mundiais, liderados pelo capital transnacional e com base na exploração de mão de obra barata, a devastação ambiental ea financeirização mostra os seus limites verdadeiros. Mas o grande negócio visa restabelecer o processo de aumento de capital, poder, riqueza e conhecimento, independentemente da vida humana e do metabolismo social estão ameaçados de várias maneiras.

Palavras-chave: crise, crise de civilização, do desenvolvimento desigual, a acumulação centralizada, metabolismo social global

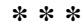

\section{Introducción}

La estrategia de acumulación mundial centralizada, la llamada globalización neoliberal, desplegada en las últimas tres décadas y media, articula nuevas modalidades de generación y apropiación de riqueza que le permite a los monopolios y oligopolios transnacionales acceder a fuentes de ganancia extraordinaria: 1) una nueva división internacional del trabajo basada en la configuración de cadenas globales de producción y el uso masivo de fuerza de trabajo barata (Delgado y Wise y Márquez, 2009); 2) la incorporación de la mayoría de los recursos naturales al proceso de valorización de capital, tanto de la litosfera como de la biosfera (Mora, 2009); 3) la privatización de medios de producción y sectores económicos estratégicos (Petras, 2005); 4) la sobreexplotación del trabajo directo, generación de una desbordante sobrepoblación e incremento de la migración forzada (Delgado y Wise y Márquez, 2009), y 5) la privatización del conocimiento mediante la propiedad intelectual y explotación del "capital humano", es decir, la pretensión de subsumir realmente el trabajo científico-tecnológico (Mora, 2009), donde también participa la migración de trabajadores altamente calificados.

No obstante, el capitalismo neoliberal afronta en nuestros días una crisis general que interpela a la humanidad acerca de seguir otorgando primacía a los intereses del capital o poner en el centro la necesidad de mejorar sustancialmente las condiciones de vida y trabajo de la mayoría de la población y de garantizar la reproducción de la vida humana en simbiosis con su entorno planetario. El primer camino reclama la aplicación de programas de rescate de empresas, o mejor dicho, de empresarios y sus monopolios y oligopolios, en respaldo al proceso de concentración y centralización de capital subyacente a la crisis. ${ }^{1}$ Este camino significa mantener indemnes algunos de los soporte clave de la acumulación mundial centralizada, como la extenuante explotación del trabajo inmediato — aunado a la 
tentativa de controlar el trabajo científico-tecnológico- y la depredación del medio ambiente, y sólo plantea regular la especulación financiera desorbitada, lo cual puede derivar en un neoliberalismo regulado por el Estado. La otra opción significa colocar en el centro el sistema de reproducción de la vida humana en el planeta, dentro del proceso de metabolismo social humanidad-naturaleza. Esta alternativa entraña la necesidad de generar cambios profundos en las estructuras de la sociedad capitalista y en el entramado institucional y político que le da soporte, en beneficio de la mayoría de las clases sociales que ha sido paulatinamente despojada de sus medios de producción y subsistencia, expuesta a condiciones altas de explotación laboral, excluida de los procesos de producción social y generación de conocimiento, confinada a espacios de hacinamiento y servicios precarios, expuesta a la compra de alimentos y medicinas caros, pese a su abundancia en el mercado, aunado al hecho de que la violencia social y estatal se ha desatado por todos los rincones del planeta y la militarización ha significado en distintos ámbitos geográficos una escalada mortal. Esta opción no se inscribe en un abstracto humanitarismo, que no identifica las relaciones de conflicto y desigualdad prevalecientes en la sociedad capitalista, sino que reclama la necesidad de ir al fondo del problema y plantear estrategias posneoliberales y poscapitalistas, porque, al final de cuentas, bajo el comando del gran capital transnacionales, no hay opciones viables para la mayoría de la población.

Bajo el paraguas de la visión dominante, la actual crisis del capitalismo mundial está circunscrita en la órbita económica y, más precisamente, en la financiera. Estados Unidos configura su epicentro, por lo que para el resto de los países se crea la imagen de que la crisis "viene de fuera". El móvil se ubica en la desregulación del mercado y la codicia y especulación del capital financiero. El factor detonante radica en el estallido de una burbuja especulativa del sector hipotecario debido a la irresponsable colocación de créditos incobrables entre población de bajos salarios o ingresos inestables y a la propagación y negociación sucesiva de estos créditos entre diversas instancias financieras con el afán de obtener ganancias prontas y abundantes. La respuesta política más socorrida descansa en los programas estatales de rescate de las grandes corporaciones financieras e industriales mediante la transferencia de multimillonarios recursos públicos, sin que exista transparencia sobre su uso. La tónica ha sido garantizar la solvencia y riqueza de empresarios y accionistas, y no el rescate de empresas, empleos y población excluida y desposeída. Además se plantea regular al capital financiero y promover una mayor participación del Estado. Esta estrategia que se presenta con la investidura de un keynesianismo redivivo, por el momento encubre un neoliberalismo regulado por el Estado.

En el presente artículo se pretende hacer un análisis crítico de la crisis del capitalismo contemporáneo que supere la visión dominante, que la caracteriza como una crisis financiera, a fin de vislumbrar sus causalidades históricas, estructurales y estratégicas, y tomar conocimiento de su carácter multidimensional y de largo plazo. En esa perspectiva, ensayamos una ca- 
racterización de la crisis en varios planos y niveles, al tiempo en que identificamos sus principales nudos críticos o paradojas y la serie de respuestas teóricas y políticas que están en la palestra. La crisis se presenta como una depresión de la economía mundial que fractura el proceso de valorización luego de una severa caída general de la tasa de ganancia y posterior a un periodo con altas tasas de ganancia merced a mecanismos como la desvalorización laboral, abaratamiento de recursos naturales, financiarización de la economía y transferencia de excedentes de la periferia hacia el centro del sistema. La ruptura de las dinámicas de financiamiento, producción, distribución y consumo, tiene como telón de fondo un proceso de sobreacumulación, donde a la sobreproducción le corresponde el desplome del consumo masivo. Pero más allá de la crisis de valorización, también postulamos que se trata de una crisis civilizatoria que pone al desnudo los límites de la acumulación mundial centralizada basada en la superexplotación laboral, la devastación ambiental y la financiarización de la economía mundial. La idea es que tras la actual depresión de la economía mundial subyace una crisis multidimensional de gran profundidad, amplitud y duración que pone en predicamento el proceso de metabolismo social, con lo que no sólo vulnera las principales fuentes de la riqueza social (humanidad y naturaleza), sino que también pone en serio peligro la vida humana en vastas zonas del planeta.

\section{Debate sobre la crisis del capitalismo}

Hoy en día, el capitalismo afronta una severa crisis de alcance mundial que ha sido motejada, de manera reduccionista, como una crisis financiera que hizo eclosión en Estados Unidos, nada menos que el centro del sistema capitalista mundial, debido a la desregulación del sistema financiero y a la codicia y especulación del capital financiero, que en la búsqueda de mayores ganancias se desprendió de la llamada economía real y recurrió a instrumentos financieros como la titularización, sucuritización, bursatilización, es decir, lo que se ha dado en llamar la financiarización. Bajo ese mecanismo, las superganancias del capital transnancional, los fondos soberanos, los fondos de inversión y otros recursos financieros ingresaban a la frenética órbita del capital ficticio que deambulaba los intersticios del sistema mundial, con el respaldo de las nuevas tecnologías de la información y la comunicación y la aquiescencia de los Estados nacionales, en la búsqueda de ganancias mayúsculas y prontas. Las estafas estuvieron a la orden del día. Sin embargo, correspondió a los créditos chatarra otorgados a población de bajos recursos o ingresos irregulares de Estados Unidos, entre ellos los inmigrantes, los nuevos pobres, presionar para que explotara la burbuja del sector hipotecario. Los pobres son invocados, bajo esta interpretación, como el eslabón más débil que detonó la gran crisis. Los efectos nocivos pronto trasminaron en la industria de la construcción, donde se ocupa una buena porción de inmigrantes, y al resto de la economía de Estados Unidos y del mundo. Ahora, esa burbuja toma las dimensiones de una depresión económica mundial. 


\section{Tabla 1. Debate sobre la crisis del capitalismo contemporáneo}

\begin{tabular}{|l|l|}
\hline Enfoque teórico & \multicolumn{1}{c|}{ Explicación } \\
\hline Financiarización & $\begin{array}{l}\text { La codicia y especulación del capital financiero detona burbu- } \\
\text { jas especulativas que se trasmiten a la economía real }\end{array}$ \\
\hline Sobreproducción & $\begin{array}{l}\text { El gran capital produce una masa inconmensurable de mercan- } \\
\text { cías que afronta problemas de realización ante la caída de la } \\
\text { demanda originada por el abaratamiento laboral }\end{array}$ \\
\hline Neoliberalismo & $\begin{array}{l}\text { El modelo neoliberal ha sido incapaz de generar crecimiento } \\
\text { económico y desarrollo humano, y a profundizado las desigual- } \\
\text { dades sociales y las asimetrías entre países }\end{array}$ \\
\hline Ciclo económico & $\begin{array}{l}\text { La economía mundial experimenta ciclos que en un momento } \\
\text { conducen a la crisis, pero dentro de la naturaleza del capitalis- } \\
\text { mo existen mecanismo para reanimar el crecimiento económico }\end{array}$ \\
\hline Estructural & $\begin{array}{l}\text { La caída en la tasa de ganancia genera un quiebre el en proceso } \\
\text { de valorización que interrumpe las dinámicas de financiamiento, } \\
\text { inversión, producción, comercialización y crecimiento }\end{array}$ \\
\hline Sistémica & $\begin{array}{l}\text { El sistema capitalista mundial experimenta una crisis } \\
\text { multidimensional en lo económico, social y ambiental que re- } \\
\text { clama un cambio de sistema }\end{array}$ \\
\hline Civilizatoria & $\begin{array}{l}\text { La sociedad occidental afronta una crisis estructural y sistémica } \\
\text { de gran magnitud que pone en predicamento el proceso de me- } \\
\text { tabolismo social hombre-naturaleza y atenta contra las fuentes } \\
\text { de la riqueza social }\end{array}$ \\
\hline
\end{tabular}

Fuente: Elaborado con base en Márquez (2009a).

La tesis financista no marcha sola, compite con otras explicaciones (véase tabla 1). La tesis de sobreproducción identifica una contradicción entre la desbordante capacidad productiva del gran capital y la política de abaratamiento laboral que desemboca en el declive de la demanda, en una crisis de realización (Katz, 2009). Para una pléyade de analistas, el neoliberalismo está en crisis debido a su incapacidad congénita para generar crecimiento sostenido y desarrollo humano, y representa además el fracaso de las políticas de ajuste estructural y de la institucionalidad capitalista encabezada por el FMI, BM y OMC (Bello, 2008). Aunque el neoliberalismo, en tanto proyecto de clase, brinda buenos resultados en su propósito de concentrar capital, poder y riqueza en pocas manos. Los teóricos del ciclo económico encuentran dificultades serias para explicar la trayectoria mecánica del capital, por lo que infructuosamente esperan una quinta ola expansiva (Beinstein, 2009). Desde el sistema-mundo y del análisis geopolítico, se anticipa el derrumbe de Estados Unidos como potencia hegemónica mundial (Wallerstein, 2005; Arrighi, 2007), y el advenimiento de una nueva era 
comandada por una gran potencia, como la Unión Europea o Japón, o por potencias emergentes como Brasil, Rusia, India y, principalmente, China. Otros autores identifican una severa crisis estructural ante la caída generalizada de la tasa de ganancia y la imposibilidad de recomponer una ciclo de valorización de largo aliento (Vasapollo, 2008). Desde una visión más abarcadora, la crisis cimbra al sistema capitalista mundial en su conjunto y articula la crisis de valorización y con una multiplicidad de crisis, como la alimentaria y la energética (Petras, 2009; Veltmeyer, 2009; Beinstein, 2009; Bartra, 2009). Más aún, se postula la idea de crisis civilizatoria para evidenciar el riesgo no sólo del proceso de valorización de capital sino de la organización de la sociedad contemporánea y la existencia de la vida humana en diversos ámbitos del planeta (Hinkelammert y Mora, 2008; Dierckxsens, 2009a; Márquez, 2009a).

En términos generales, podemos advertir que las siete explicaciones sobre la crisis desembocan, al final de cuentas, en tres vertientes paradigmáticas (véase tabla 2). La primera corriente agrupa la visión convencional u ortodoxa desde la óptica neoclásico y neoliberal, el llamado pensamiento único, y se ampara en la idea de que la crisis es un fenómeno localizado, sectorizado y de corto plazo, con la atenuante de que su respuesta plantea el rescate de los grandes capitales por el Estado, sin importar que esta disposición contravenga su ideología neoconservadora, pero sin que esto signifique una confesión de parte sobre la invalidez de sus proclamas políticas. La segunda corriente, que aglutina a la perspectiva heterodoxa, brinda cobijo a posiciones neokeynesianas y socialdemócratas, es decir, cubre el espectro político de centro izquierda, aunque tiene puntos de coincidencia en la caracterización de la crisis con la visión dominante en el sentido de que se trata de un fenómeno localizado, sectorizado y coyuntural, sólo que achaca la responsabilidad a la desregulación neoliberal y a la codicia de los financistas, por lo que reclama la implementación de nuevas regulaciones y una mayor participación del Estado en las tareas de la promoción del desarrollo, pese a que hace una crítica matizada al neoliberalismo no cuestiona los fundamentos del capitalismo. Su propuesta, en todo caso, pretende rescatar o reformar al capitalismo neoliberal. La tercer vertiente analítica es crítica por antonomasia y caracteriza a la crisis, desde distintos ángulos, como estructura, sistémica y civilizatoria, además de que le coloca los atributos de global, multidimensional y de largo plazo. Si bien admite que el gran capital y el Estado tienen mano en la aplicación de políticas de rescate, advierte sobre el hecho de que éstas no hacen más que postergar el advenimiento de nuevas y quizá más profundas crisis. La única salida real sería un cambio estructural y sistémico, una nueva civilización. No obstante, reconoce que a la fecha no existe un agente colectivo alternativo capaz de confrontar el poderío del gran capital y sus agentes que dan cuerpo al llamado imperialismo colectivo. 
Tabla 2. Enfoques sobre la crisis

\begin{tabular}{|c|c|c|c|}
\hline $\begin{array}{l}\text { Enfoque/ } \\
\text { Características }\end{array}$ & Convencional & Heterodoxo & Crítico \\
\hline Ubicación & Estados Unidos & Estados Unidos & $\begin{array}{l}\text { Sistema capitalista } \\
\text { mundial }\end{array}$ \\
\hline Definición & Financiera & Financiera & $\begin{array}{l}\text { Estructural, sisté- } \\
\text { mica y civilizatoria }\end{array}$ \\
\hline Causa & $\begin{array}{l}\text { Especulación y co- } \\
\text { dicia }\end{array}$ & $\begin{array}{l}\text { Desregulación, es- } \\
\text { peculación y codi- } \\
\text { cia }\end{array}$ & $\begin{array}{l}\text { Neoliberalización, } \\
\text { sobreproducción, } \\
\text { superexplotación } \\
\text { laboral y depreda- } \\
\text { ción ambiental }\end{array}$ \\
\hline Detonador & $\begin{array}{l}\text { Burbuja hipoteca- } \\
\text { ria }\end{array}$ & $\begin{array}{l}\text { Burbuja hipoteca- } \\
\text { ria } \\
\text { Financiarización }\end{array}$ & $\begin{array}{l}\text { Sobreacumulación, } \\
\text { financiarización y } \\
\text { declive de hege- } \\
\text { monía de Estados } \\
\text { Unidos }\end{array}$ \\
\hline Sector & $\begin{array}{l}\text { Financiero-hipote- } \\
\text { cario }\end{array}$ & $\begin{array}{l}\text { Financiero-hipote- } \\
\text { cario }\end{array}$ & $\begin{array}{l}\text { Capital ficticio } \\
\text { Capital transnacio- } \\
\text { nal }\end{array}$ \\
\hline Amplitud & Sistema financiero & $\begin{array}{l}\text { Sistema financiero } \\
\text { con repercusiones } \\
\text { en economía real }\end{array}$ & Economía mundial \\
\hline Temporalidad & $\begin{array}{l}\text { Corto plazo (2008- } \\
\text { 2009) }\end{array}$ & $\begin{array}{l}\text { Corto plazo (2008- } \\
\text { 2009) }\end{array}$ & $\begin{array}{l}\text { Largo plazo, se re- } \\
\text { monta a la década } \\
\text { de los } 70 \text { s }\end{array}$ \\
\hline Respuesta & $\begin{array}{l}\text { Rescate de grandes } \\
\text { capitales } \\
\text { Política neoliberal } \\
\text { Flexibilidad labo- } \\
\text { ral }\end{array}$ & $\begin{array}{l}\text { Regulación } \\
\text { Participación del } \\
\text { Estado } \\
\text { Programas de in- } \\
\text { versión y empleo }\end{array}$ & $\begin{array}{l}\text { Cambio estructu- } \\
\text { ral y sistémico } \\
\text { Nueva civilización }\end{array}$ \\
\hline
\end{tabular}

El análisis predominante de la crisis contemporánea está orientado a preservar al sistema capitalista y a rescatar a los grandes capitales centrales. La visión dominante presenta a la globalización como un fenómeno de alcance mundial inevitable, sin alternativas, y al cual hay que asumir como un reto. Para ello hay que abrir los mercados, ofrecer condiciones idóneas a la inversión extranjera y afrontar el reto de la competitividad, donde el Estado debe generar un clima favorable a los negocios, particularmente a las grandes corporaciones multinacionales, abaratar la fuerza de trabaja barata, transferir recursos públicos al sector privado, además de implementar 
una estrategia de venta de las ciudad y el territorio, donde priman los intereses del capital, y no los de la población. Este tipo de políticas se aplican indistintamente por gobiernos de derecha, centroizquierda e izquierda, salvo algunas excepciones de gobiernos que intentan resistirse al neoliberalismo y ejecutan políticas que pueden ser designadas bajo el concepto de nacionalismo radical. Desde esta concepción, la crisis actual del capitalismo es de tipo financiero o de la política neoliberal, por lo que el Estado puede jugar un rol más activo para revertir el ciclo recesivo de la economía y recomponer el rumbo. Entre las políticas planteadas, de corte neokeynesiano, se contempla el rescate de empresas, aunque más bien sea de empresarios, no de empleos ni deudores de las clases populares. No obstante, no se pone en tela de juicio la llamada globalización que, se dice, es un fenómeno que llegó para quedarse.

No obstante, la actual crisis no es un tema de coyuntura ("un catarrito", dijera un funcionario del gobierno mexicano), o una externalidad ("la crisis que viene de fuera") o un problema localizado (en Estados Unidos) o sectorizado ("crisis financiera"). Desde nuestra perspectiva se trata no sólo de una crisis de valorización de capital sino también del deterioro de las bases económicas, sociales y ambientales que le dan sustento. Es decir, una crisis de la estrategia de reestructuración y expansión neoliberal que se presenta como crisis general del capitalismo mundial, la tercera en su género, después de las acaecidas en las décadas de los treinta y setenta del siglo pasado. Se presenta como una depresión económica mundial porque representa una fractura colosal de los procesos de financiamiento, inversión, producción, crecimiento y distribución, que además de propiciar una caída de la tasa de ganancia, trae consigo una crisis de realización y un complejo proceso de destrucción de capitales (concentración y centralización de capital). Además, exhibe una de las principales contradicciones del sistema: la sobreproducción. El neoliberalismo ha generado una enorme capacidad de producir mercancía, al expandir la órbita del mercado, la privatización, la explotación de trabajo barato y la devastación ambiental, pero lo ha hecho a costa de deprimir los salarios, desmantelar la economía de subsistencia, cancelar o menguar los apoyos a la economía social. El resultado ha sido un deterioro del consumo masivo, merced al abaratamiento laboral y a la proliferación del crédito masivo moroso, y una abundancia de mercaderías sin compradores. Pero más aún, el afán de ampliar los márgenes de ganancia ha deteriorado las condiciones materiales de vida y trabajo de la mayoría de la población. Al punto en que la vida humana es catalogada como un recurso o mercancía desechable.

\section{Carácter estructural, sistémico y civilizatorio}

La expansión del capitalismo neoliberal y el régimen de acumulación centralizado han generado una propensión a crisis recurrentes en distintas regiones del planeta, particularmente en el mundo periférico. En las últimas tres décadas se tiene conocimiento de seis crisis importantes. Estas crisis han cumplido el cometido de brindar salidas al capitalismo mundial 
para depurar capitales sobrantes y profundizar la concentración de capital, en este propósito también han hecho su aparición las guerras desatadas por los países imperiales en países periféricos con la finalidad de apropiarse de abastos de recursos naturales, como el petróleo en el caso de Irak, o de derrocar o persuadir a regímenes políticos opositores con influencia geoestratégica. Como correlato, se ha generado una dinámica destructora de empresas, empleos, poblaciones, ecosistemas y culturas.

La acumulación mundial centralizada ha propiciado la concentración de capital, poder, riqueza y conocimiento en manos de una delgada élite social en el plano transnacional y nacional. No obstante, los mecanismos centrales de la gestión del capitalismo mundial están experimentando un deterioro:

1) La financiarización de la economía mundial. La canalización de ingentes cantidades de ganancias, ahorros y fondos hacia la inversión financiera, principalmente bajo pautas especulativas, configura una fuente apetecible de ganancias ficiticias. Remesas fabulosas de dinero fueron canalizadas mediante complejos instrumentos financiero y estrategias como la titularización, securitización y bursatilización para generar una impresionante burbuja financiera especulativa. Las grandes corporaciones canalizaron sus ganancias hacia la inversión financiera, y no tanto a la inversión productiva o el financiamiento a la innovación, con el señuelo de acceder a ganancias extraordinarias. Los países periféricos han sido partícipes del proceso de financiarización mediante la canalización de ganancias, fondos soberanos, fondos de pensiones y ahorros hacia fondos de inversión inmersos en estrategias especulativas del capital financiero, que prometían ganancias prontas y abundantes, pero sin tener sustento en la economía real. El sistema financiero internacional se colapsó, al punto en que el crédito entre los propios segmentos e instancias del capital financiero quedó pronto empantanado.

2) La sobreacumulación: sobreproducción y su contracara, el subconsumo. La expansión capitalista generó una enorme capacidad de producción derivado de la ampliación de cadenas globales de producción, la incorporación de abundantes recursos naturales baratos y la sobreoferta de fuerza de trabajo barata. Sin embargo, uno de los soportes de este boom fue la contención y disminución real de los salarios, lo cual repercutió en un desplome de la capacidad de consumo masivo. Esto derivó claramente en una crisis de realización. El cúmulo de mercancías no tenían salida inminente en el mercado vía consumo. El recurso al crédito dinamizó el consumo, pero pronto sucumbió bajo los meandros de la financiarización. El control de las grandes corporaciones transnacionales en la producción industrial, la agricultura y los servicios produce concentración y transferencia de riqueza, concentración y destrucción de capital y concentración de ingreso y expansión de la pobreza, además de que sus operaciones corporativas devastan el medio ambiente puesto que sus requerimientos en términos de cantidad (lo más posible) y de tiempo (lo menos posible) atentan en contra de la capacidad de renovación de la materia natural, y arroja como 
resultado contaminación, devastación, erosión, deterioro. La mayoría de las veces se trata de daños irreversibles, que no sólo agreden el medio ambiente sino que trastocan el llamado metabolismo social hombre-naturaleza.

3) La superexplotación del trabajo y la exclusión social. Desde una perspectiva cruda, para el capitalismo, la única crisis que tiene relevancia es cuando se presenta una caída general en la tasa de ganancia, porque significa una crisis del proceso de valorización, es decir, una fractura en las dinámicas de financiamiento, inversión, producción, distribución y consumo. Poco importan las diversas expresiones de crisis humanitaria, como la pobreza, desempleo, hambrunas, enfermedades, en todo caso esos son daños colaterales, que eventualmente pueden resarcirse cuando se recomponga el ciclo natural de los negocios. La superexplotación del trabajo significa no sólo la contención salarial y el empobrecimiento familiar, sino también la exposición a riesgos y peligros laborales, el desgaste prematuro de la fuerza laboral y la posibilidad de ser despedido y excluido de la órbita de la producción y el consumo. No obstante, bajo el influjo del capitalismo neoliberal se han recrudecido los problemas sociales, al punto en que se pone en riesgo, cuando menos en vastas zonas del planeta, la existencia y reproducción de la vida humana. El rasgo consustancial al capitalismo neoliberal es la insustentabilidad social.

4) La depredación de la naturaleza. Los recursos naturales renovables y no renovables son incorporados a la órbita de la valorización del capital sin importar los daños ocasionados al ecosistema o el despojo al que son sometidos pueblos enteros con la finalidad de explotarlos. El criterio de máxima ganancia en el menor tiempo posible resulta demasiado frenético como para que los recursos renovables se regeneren, y devastador para aquellos que no son renovables. Simultáneamente se están generando problemas contiguos como la contaminación, el cambio climático y en algunos casos la escasez de recursos vitales, como el agua, y necesarios, como el petróleo. Por si fuera poco, el intercambio desigual en materia ambiental especializa a los países subdesarrollados como proveedores de materias primas baratas sin importar los daños ambientales y sociales vinculados. Aún más, la relación simbiótica entre la humanidad y la naturaleza se ve severamente fracturada, no por problemas puramente técnicos, como aducen la mayoría de informes en la materia, sino por las relaciones sociales de producción dominantes a nivel mundial.

En tal sentido, la actual crisis, además de expresar una depresión mundial de la economía, se emparenta con una crisis de reproducción de la vida humana (Hinkelammert y Mora, 2008). Esto último no sólo tiene una connotación ética y humanista preocupada por velar por la satisfacción de las necesidades básicas de la población y del acceso a recursos productivos y de subsistencia, sino que también pone en predicamento una de las principales fuentes de riqueza social, la fuerza de trabajo y la naturaleza. Visto en perspectiva, la actual crisis es sistémica (porque afecta al sistema capitalista en su conjunto), es estructural (porque se expresa en múltiples dimensiones y niveles) y es civilizatoria (porque vulnera el proceso de 
matabolismos social hombre-naturaleza y coloca en una encrucijada a los fundamentos de la valorización). Esta explicación difiere notablemente de la idea dominante que ofrece una interpretación por demás reduccionista: localizada (en Estados Unidos), sectorizada (sector financiero), acotada (corto plazo) y ordinaria (basta con la intervención del Estado para la recuperación). Sin embargo, tampoco se adhiere a explicaciones mecánicas que vislumbran el fin del capitalismo y el pase automático a una nueva sociedad, o más modestamente al fin del neoliberalismo y al triunfo de los sectores excluidos, sino que advierte sobre el hecho de que pese a su envergadura y profundidad, la crisis encuentra más salidas dentro del capitalismo y dentro del neoliberalismo por el solo hecho de que el único agente colectivo con capacidad de respuesta es el gran capital, que amalgama a los grandes monopolios y oligopolios transnacionales, los Estados centrales y periféricos, los organismos internacionales, los medios de comunicación, entre otros actores importantes. En cambio, las clases, movimientos y actores alternativos están disgregados y carecen de un proyecto alternativo. Empero, las respuestas ensayadas por el gran capital (el salvataje: transferencia de recursos públicos a las grandes corporaciones financieras e industriales) pueden resultar a la postre insuficientes porque no acometen las causas estructurales de fondo y postergan la irrupciones de nuevas crisis, quizás más graves. Si la crisis es estructura, sistémica y civilizatoria, la respuesta acertada estaría apuntada en el cambio estructural, sistémico y civilizatorio, es decir, en pauta posneoliberal y postcapitalista, pero no existe la fuerza social para materializarlo.

\section{Complejidad de la crisis}

La presente crisis es, en principio, una crisis general del sistema capitalista neoliberal que se expresa como una severa depresión económica mundial, que a su vez significa una declinación de la estrategia de reestructuración y expansión neoliberal basada en la superexplotación del trabajo inmediato, la depredación ambiental y la financiarización de la economía mundial. Pero más aún, se trata de una compleja crisis civilizatoria con cariz multidimensional que expone los límites de la valorización mundial de capital por cuanto atenta, como lo había advertido Marx (1975), en contra de los fundamentos de la riqueza: el ser humano y la naturaleza, y porque pone en predicamento el sistema de vida en el planeta, es decir, el metabolismo social. Desde esta perspectiva, el capitalismo neoliberal se erige como una poderosa maquinaria destructora de capital, empleo, población, infraestructura, conocimiento y cultura. Su criterio central, la maximización de ganancia, está en las antípodas de la reproducción social y las condiciones biológicas para la producción.

Un punto importante para tomar en cuenta en el análisis, es el hecho de que la referida complejidad de la crisis logra encubrirse, provisionalmente, por el gran descalabro que significa la depresión económica mundial. Para ir más allá de la simple apariencia, es indispensable entonces adoptar una perspectiva histórica, estructural y estratégica. Además de la 
depresión económica, que da cuenta de una crisis de valorización generalizada, la crisis tiene que enunciarse en plural, como las crisis, o la convergencia de las varias crisis, puesto que posee un desfigurado rostro multidimensional. Esta estrategia analítica necesita superar la tesis financista, anclada en el análisis de las relaciones intracapitales, y advertir cómo la acumulación mundial centralizada acrecienta el dominio del capital sobre el trabajo, la naturaleza, el dinero y el Estado, bajo una lógica depredadora, que a la vez que se apropia y domina, destruye. El capitalismo neoliberal polariza la riqueza en beneficio de las grandes corporaciones transnacionales, y en detrimento de la clase trabajadora y el Estado-nación, al tiempo en que genera ganancias fabulosas, que bajo la argucia del capital ficticio, han sido canalizadas, ciertamente, a la especulación financiera e hipotecaria. Estas súperganancias proceden de una extenuante explotación del trabajo inmediato, la privatización de fondos de pensiones, la transferencia de capital al centro, el pago de deuda externa y la compra de bonos y dólares con reservas de Estados Unidos, además de la sobreexplotación de recursos naturales (Caputo, 2009).

Más allá de su contenido como crisis general de valorización, la crisis es de largo plazo, de todo el sistema y es además multidimensional. Por tanto, se trata de una crisis estructural y sistémica, una crisis civilizatoria que prohíja una y varias crisis. No se trata de una superposición, sumatoria o concatenación de crisis, sino que se refiere a expresiones del agotamiento de la estrategia de expansión capitalista neoliberal, basada en estrategias espurias, como la explotación extenuante del trabajo inmediato, la superexplotación del medio ambiente y la financiarización de la economía mundial. Estas estrategias tratan como mercancías a elementos que de origen no son mercancías: la humanidad, la naturaleza y el dinero. Es decir, el capital amplía su dominio sobre las formas de reproducción de la vida humana y el metabolismo social hombre-naturaleza. Este tratamiento desmesurado pone en riesgo la existencia misma de la vida humana en varios ámbitos del planeta. Además de sus componentes financiero y depresivo, la crisis civilizatoria posee, cuando menos, nueve caras igualmente tenebrosas:

1) Crisis laboral. Los países subdesarrollados pierden soberanía laboral, es decir, la capacidad de generar el suficiente empleo formal de calidad que demanda su población en edad de trabajar. La OIT estima que a finales de 2009 puede haber hasta 239 millones de desempleados en el mundo (El Universal, 29 de mayo de 2009).

2) Crisis alimentaria. El orden agroalimentario global antepone los intereses de las empresas transnacionales, desmantela los sistemas de producción de los países subdesarrollados y sus modos de vida campesino, y genera el problema de la pérdida de soberanía alimentaria y la insustentabilidad social. Se estima que más de mil millones de personas están al borde de la muerte por hambre (FAO, 2009).

3) Crisis de subsistencia. Según cifras de la FAO para 2007, dentro 
del rango de pobreza se ubicaban 4,750 millones de personas en el mundo; casi la mitad de la población mundial, más de 2,800 millones de personas en el mundo sobreviven con menos de 2 dólares al día y 1,200 millones de personas lo hacen con un dólar o menos al día (ONU, 2005). Del mismo modo, la ONU estima que al menos mueren unas 50 mil personas al día en el mundo a causa de la pobreza extrema (El Universal, 19 de septiembre de 2007).

4) Crisis ambiental. La desproporción en el consumo de recursos naturales en el sistema capitalista mundial es desigual: el 20\% de la población mundial, concentrada en los países centrales del norte consume 80\% de los recursos naturales (Dierckxsens, 2009b). La voraz dinámica de acumulación destruye lo que la naturaleza tarda millones de años en construir.

5) Crisis energética. El control oligopólico de los mercados de consumo convierte a los energéticos en una mercancía volátil expuesta a ataques especulativos que castiga, sobre todo, a los países subdesarrollados dependientes de los energéticos, ya sea porque se especializan en su producción y exportación o porque, al carecer de ellos, dependen de su importación. Diversos analistas anuncian el final de la era de petróleo barato: únicamente 14 de los 54 países productores de petróleo están todavía incrementando la extracción de crudo (Ghanta, 2009).

6) Crisis migratoria. Enormes contingentes de población devienen en redundantes o desechables para las necesidades de valorización del capital. La cantidad de migrantes laborales que van de sur a norte y el volumen de las remesas que envían a sus países de origen han experimentado un crecimiento sin precedentes en todo el mundo. La cantidad de migrantes ha superado el doble de su magnitud en los últimos 25 años, alcanzando una marca histórica de 190 millones en 2005. Una proporción creciente de esos migrantes son migrantes laborales que se trasladan del sur al norte. El flujo de remesas del norte al sur, que son un componente salarial abocado a subsanar la subsistencia familiar en lugres de origen, ha crecido aún más, de 48 mil millones de dólares en 1995 a 199 mil millones de dólares en 2006.

7) Crisis política. Un andamiaje de poder transnacional aglutina a corporaciones transnacionales, Estados imperiales, organismos internacionales y partidos políticos en torno al neoliberalismo. No obstante, hoy se registra una crisis institucional, vista como una pérdida de legitimidad de las instituciones neoliberales, estatales y financieras. Sin embargo, la concentración de poder ha sido tan contundente que ha desmantelado proyectos y agentes políticos que podrían encarnar la alternativa y el cambio social. En la actualidad, no hay un agente colectivo alternativo al gran capital y sus intereses.

8) Crisis cultural. El pensamiento único representado por la ideología neoliberal se ha inoculado en la sociedad como sentido común, con el respaldo de los medios masivos de comunicación, dominados por instancias empresariales monopólicas, plegadas al neoliberalismo. Ante el agra- 
vamiento de las desigualdades sociales, predomina una sensación de desánimo y apatía, y en menor medida, de resistencia y rebelión. Se minimiza la cultura, como espacio de crítica, creación y educación, para reducirla a su mínima expresión, como entretenimiento banal y desinformación.

9) Crisis teórica. La generación del conocimiento social afronta un momento de letargo ante la imposición del pensamiento único y la difusión del posestructuralismo. Asimismo, la adopción de marcos analíticos microsociales inconexos y descontextualizados. Como resultado, acontece una ruptura en epistemológica entre lo macro y lo micro, estructura y sujeto, lo global y lo local, el largo y corto plazos (Márquez, 2009b).

\section{Paradojas de la crisis sistémica}

La amplitud y profundidad de la crisis estructural y sistémica del capitalismo mundial ha prohijado cuatro paradojas sintomáticas (véase tabla 3), derivadas del estancamiento de los ejes de la estrategia de acumulación mundial centralizada revisadas previamente.

1. La sobreacumulación genera concentración de capital, poder, riqueza y conocimiento, pero destruye empresas, empleos, infraestrucura y cultura. La convulsión del sector financiero y productivo, la bancarrota y caída de la rentabilidad, anuncian que la crisis general del capitalismo trae consigo una enorme fuerza destructora de capitales considerados por la racionalidad del sistema como sobrantes. Esto significa que está en operación un proceso de reconcentración de capital, con el auxilio del Estado y sus programas de "rescate", en manos de los monopolios y oligopolios transnacionales que señorean la globalización neoliberal. Estas depurativas aguas anegan la dinámica económica, pero también responden a la necesidad de abaratar capitales. Debido a que la crisis destruye capital, empleos e infraestructura, el gran capital reclama la participación del Estado para que transfiera recursos públicos a las grandes corporaciones, las cuales ejecutan, a su vez, una reconcentración de capital. Más que una política keynesiana, se trata de un rescate del neoliberalismo por el Estado bajo la conocida fórmula de privatizar los beneficios y socializar las pérdidas.

2. La profundización del desarrollo desigual centro-periferia permite la extracción de excedente y la explotación laboral de la periferia, pero no puede detener el declive de Estados Unidos como principal potencia capitalista del orbe. De manera paulatina e inexorable, la dinámica destructiva deviene de los mecanismos del desarrollo desigual, que desmantelan las bases nacionales de acumulación en la periferia y transfieren excedentes, recursos naturales y humanos en beneficio de la acumulación centralizada. ${ }^{2}$ La expansión capitalista neoliberal ha prohijado una modalidad de acumulación centralizada bajo el comando de los monopolios y oligopolios transnacionales y el respaldo político de los Estados imperialistas y los organismos internacionales. Las grandes corporaciones 
(capital monopolista) acrecientan su supremacía gracias a ingentes procesos de fusión, aunque también actúan por separado, entre el capital productivo, financiero y comercial. Esto nos remite a un colosal proceso de concentración y centralización de capital. Sin embargo, bajo esta modalidad no se está creando nuevo capital, ni un gran proceso de innovación tecnológica, ni una gran masa de plusvalor, sino que se amasa capital muerto bajo mecanismos de apropiación privada (Petras, 2005). En este caso, la inversión extranjera directa (IED) actúa como fuerza motora o caballo de Troya, aunque está investida de una mitología que le confiere atributos de motor del desarrollo, cuando realmente actúa como una colosal fuerza extractora de excedentes. La reincorporación de la periferia a la dinámica de acumulación centralizada profundiza el desarrollo desigual e incrementa las ganancias del capital transnacional. Estos países participan como proveedores de materias primas y fuerza de trabajo barata según las necesidades de las cadenas globales de producción, a cambio de vulnerar sus capacidades internas de acumulación.

\section{La superexplotación del trabajo y la naturaleza significan la} generación de nuevas fuentes de ganancia, pero también la fractura del proceso metabólico. La globalización neoliberal da origen a la economía mundial del trabajo barato que convierte a los países subdesarrollados en exportadores de gente. La expansión de la fuerza de trabajo, acompañada de la política de precarización laboral, significa una sobreoferta de trabajo a disposición del gran capital. Los países periféricos del planeta se convierten en abastecedores de trabajo barato en aras de la reestructuración capitalista. El régimen de superexplotación del trabajo barato, amén de basarse en la destrucción de medios de producción y subsistencia, pone en entredicho la reproducción social y convierte a los trabajadores en personas desechables. La periferia pierde soberanía laboral, entendida como la capacidad para generar suficientes fuentes de trabajo formal de calidad para su población (Márquez, 2008). En conjunto, la explotación del trabajo alcanza varias formas bajo el capitalismo neoliberal, no sólo el asalariado, sino que también subsume al campesino, femenino, informal, improductivo, infantil y forzado. En la órbita del trabajo productivo explota de manera exhaustiva el trabajo directo y de manera formal el trabajo científicotecnológico (Mora, 2009).

4. Los programas de rescate de los grandes capitales con recursos públicos asociados a políticas de mayor explotación laboral y natural representan una modalidad de neoliberalismo regulado que ahonda la crisis civilizatoria. Desde la visión economicista propalada por la mayoría de analistas y medios de comunicación, la voracidad de los especuladores financistas sólo puede ser contenida mediante la intervención del Estado para regular el sistema financiero y para rescatar empresas en apuros, porque las grandes corporaciones transnacionales, además de ser íconos del sistema mundial, constituyen el agente principal de la estrategia de acumulación centralizada. Esta estrategia de rescate no deja de ser conspicua, porque se trata de un proceso de salvataje, es decir, la transferencia de sumas multimillonarias del erario público a grandes corporacio- 
nes en apuros, pero no se trata de un rescate de empresas y empleos, sino que se pretende garantizar la solvencia y riqueza de empresarios y accionistas, en modo alguno se trata de un rescate social de desempleados, pobres y desposeídos, por ejemplo, de quienes perdieron sus casas y empleos. A ellos se les puede otorgar paliativos, como despensas, albergue, becas o empleo temporal, pero hasta ahí. La consigna sigue siendo, hoy como ayer, “privatizar los beneficios y socializar las pérdidas".

Tabla 3. Paradojas de la crisis del capitalismo contemporáneo

\begin{tabular}{|l|l|l|}
\hline \multicolumn{1}{|c|}{ Paradoja } & \multicolumn{1}{|c|}{ Proceso } & \multicolumn{1}{c|}{ Contradicción } \\
\hline $\begin{array}{l}\text { Sobreacumulación: sobre- } \\
\text { producción y subconsumo }\end{array}$ & $\begin{array}{l}\text { Concentración de capital, } \\
\text { poder, riqueza y conoci- } \\
\text { miento }\end{array}$ & $\begin{array}{l}\text { Destrucción de empresas, } \\
\text { empleos, infraestructura y } \\
\text { cultura }\end{array}$ \\
\hline $\begin{array}{l}\text { Desarrollo desigual cen- } \\
\text { tro-periferia }\end{array}$ & $\begin{array}{l}\text { Extracción de excedente y } \\
\text { recursos naturales y hu- } \\
\text { manos y nueva división } \\
\text { internacional del trabajo }\end{array}$ & $\begin{array}{l}\text { Deterioro económico y } \\
\text { político de la principal } \\
\text { potencia capitalista del } \\
\text { orbe }\end{array}$ \\
\hline $\begin{array}{l}\text { Nuevas fuentes de gene- } \\
\text { ración y apropiación de } \\
\text { ganancias }\end{array}$ & $\begin{array}{l}\text { Sobreexplotación laboral } \\
\text { y ambiental }\end{array}$ & $\begin{array}{l}\text { Disrupción del proceso } \\
\text { metabólico hombre-natu- } \\
\text { raleza }\end{array}$ \\
\hline Neoliberalismo regulado & $\begin{array}{l}\text { Rescate de grandes capi- } \\
\text { tales en quiebra }\end{array}$ & $\begin{array}{l}\text { Flexibilización y precari- } \\
\text { zación laboral }\end{array}$ \\
\hline
\end{tabular}

\section{Respuestas ante la crisis}

Las respuestas o salidas a la crisis se expresan en distintos planos teóricos y políticos. En un primer ejercicio de clasificación, podemos identificar seis proposiciones diferenciadas (véase tabla 4).

1. Determinismo tecnológico. Teóricamente, se supone que las crisis capitalistas pueden ser superadas mediante la implementación de nuevas tecnologías. Recientemente, se ha planteado que las nuevas tecnologías de la información y la comunicación (TIC), aunado a la formación del llamado capital humano, que en conjunto dan cuerpo a la llamada sociedad del conocimiento o al capitalismo informacional, abrirían una nueve era de desarrollo capitalista. No obstante, la crisis misma ha dado al traste con dicho aserto. Ahora, los promotores de las nanotecnologías, plantean una idea similar: la irrupción de una nueva revolución científico-tecnológica y la apertura de una era de prosperidad para la humanidad. La nanotecnología ha sido definida como la manipulación de la materia a una microescala, nanómetros, que puede generar nuevos materiales y procedimientos. Esto tendría como soporte una convergencia de disciplinas científicas bajo nue- 
vas formas de cooperación y control del trabajo científico-tecnológico por el gran capital y el Estado, los grandes financiadores de los proyectos de innovación. Esto también repercutiría en la creación y destrucción de ramas y sectores económicos, generaría nuevas pautas de consumo y trastocaría la actual división del trabajo a nivel nacional e internacional (Foladori e Invernizzi, 2005). No obstante, es conocido el hecho de que la innovaciones tecnológica desencadenan procesos de desempleo y desigualdad, además de que no están bien precisados los efectos en la salud, dado que el móvil principal es la obtención de ganancias en el menor tiempo posible (Foladori, 2009). Más aún, lo que está en juego es la posibilidad de subsunción real o control absoluto del capital sobre la generación y aplicación del conocimiento científico y tecnológico bajo la órbita de la valorización de capital.

2. Neoliberalismo regulado. En su formulación ideológica, el neoliberalismo reniega de la regulación Estatal sobre el mercado. En la realidad, el Estado es un agente central para que el proyecto que representa el neoliberalismo se pueda implantarse y expandirse. No obstante, el diagnósticos más socorrido sobre la crisis achaca la responsabilidad de su explosión a la codicia y especulación de financistas sin escrúpulos y, los más importante, desregulados. Entre la llamada heterodoxia económica, formada principalmente por neokeynesianos, surgen fuertes llamados para que se ponga en cintura a la especulación financista, mediante la regulación estatal. Una confluencia de autores neokeynesianos y socialdemócratas plantean una reforma al proyecto de globalización mediante la regulación del capital financiero y sus estrategias especulativas. Esta perspectiva tiene su precedente en formulaciones como las del llamado posconsenso de Washington, la tercera vía y la socialdemocracia, y su impronta no es precisamente un crítica radical al sistema, sino más bien una estrategia de rescate o reforma del capitalismo, al amparo de metáforas como el rostro humano de la globalización. Esta perspectiva está anclada en la dimensión económica, el ámbito global y la función del Estado como agente regulador del mercado.

3. Retorno romántico a la comunidad. Teniendo como antecedente la crítica a la llamada modernidad occidental, la idea de progreso y el maldesarrollo, el posmodernismo postula una serie de ideas orientadas al retorno a los ámbitos de comunidad y convivencialidad, entre sus proposiciones se encuentran la de decrecimiento, posdesarrollo y buen vivir. La crisis deviene como el predominio de una fe ciega en el progreso, el industrialismo, el consumismo y la tecnología, y la concomitante destrucción o desvanecimiento de las relaciones comunitarias y sus formas primigenias de comercio, producción y consumo. Para retornar a ese ambiente se postulan principios como convivencialidad, comunidad y solidaridad. El poscapitalismo encuentra, por ejemplo, en algunas vertientes posmodernas, la idea de que las comunidades organizadas pueden generar formas de autogobierno, economías de solidaridad y culturas regionales fuera de los márgenes del capitalismo, aunque no necesariamente se desconecten por completo. 
4. Desglobalización. Desde una posición crítica hacia el proyecto que representa la globalización neoliberal, se postula la desconexión de los países subdesarrollados a ese entramado mundial comandado por los grandes capitales y los Estados centrales. Como alternativa se pronuncian distintos proyectos de reinserción a la economía mundial mediada por la configuración de nuevos esquemas de integración regional centrado en la visión e intereses de los países periféricos (Jalife-Rahme, 2007). Un ejemplo de ello es el proyecto ALBA, que articula inicialmente a los países sudamericanos que están encabezados por gobiernos de izquierda y centro izquierda. Asimismo, se plantea la necesidad de reconstruir la dinámica de desarrollo nacional bajo pautas posneoliberales, desde esa perspectiva se contempla a lo nacional como una fuerza o agente de desarrollo que tiene que ser revalorado, no bajo pautas puramente proteccionistas o centradas en los intereses oligárquicos, sino bajo preceptos de un nacionalismo desarrollista, autónomo y soberano. Desde una perspectiva más abarcadora, se postula la idea de la desglobalización como una paradigma alternativo basado en el mercado interno, la subsidiariedad, protecciones comerciales, el reemplazo del BM y FMI, entre otras disposiciones (Bello, 2009).

5. Posneoliberalismo. La idea de trascender al neoliberalismo como visión dominante en la teoría y práctica del desarrollo conjuga a sectores de las más diversas expresiones y signos ideológicos. Esto es así porque el neoliberalismo se presenta como la configuración política del capitalismo, como su expresión de pensamiento único, pero no como el capitalismo en sí mismo. Por tanto, tienen cabida expresiones que, por un lado, buscan reformar el capitalismo desde adentro, ya sea que representen a la institucionalidad capitalista, como el BM, o que desde la heterodoxia neokeynesiana, institucionalistas y desarrollistas aboguen por el retorno del Estado en al mando en las tareas del desarrollo, y, por otro lado, pretendan transcender al neoliberalismo y al capitalismo en su conjunto mediante expresiones radicales que postulan una nueva sociedad posneoliberal y poscapitalista o transcapitalista, algunas de cuyas expresiones más logradas se plasman en el ideario del socialismo como única salida, sin que exista un solo camino, una sola receta, un solo proyecto. También existen planteamiento posmodernos que se adhieren a esta zona gris del posneoliberalismo, pero no necesariamente comparten los postulados heterodoxos ni poscapitalistas. El rasgo en común de estas expresiones es que critican la ideología y política neoliberal, y se asientan en la dimensión estratégica del desarrollo, es decir, en el entramado institucional y político. De este modo, podemos hacer un recuento general de las posturas posneoliberales en los siguientes términos: a) Del capital. Los agentes del gran capital han aceptado o planteado críticas matizadas al neoliberalismo, a pesar de que ellos son los diseñadores y promotores principales de ese proyecto de alcance internacional. De este modo, se ha planteado, por ejemplo, el llamado posconsenso de Washington, la tercera vía o los objetivos del desarrollo del milenio. Pareciera ser una paradoja que los ideólogos del neoliberalismo propongan alternativas al neoliberalismo. Pero no necesariamente se están contradiciendo, sino que intentan preservar los intereses centrales del gran capital y su dinámica de acumulación mundial centrali- 
zada. Desde esta lógica, resulta irrelevante el ropaje ideológico, mientras se mantengan vigentes los intereses vitales del proceso de valorización; b) De los movimientos sociales. El neoliberalismo ha promovida la destrucción de sujetos sociales, pero al mismo tiempo ha incitado la conformación de movimientos sociales que expresan posiciones de resistencia y rebelión. Por ejemplo, el Movimiento de los Sin Tierra (MST) en Brasil, el Ejército Zapatista de Liberación Nacional (EZLN) en México o el Foro Social Mundial (FSM) y Vía Campesina a nivel internacional. Sin embargo, no existe aún un agente colectivo que tenga la capacidad de contrapeso al gran capital y sus instituciones afines. Los movimientos sociales alternativos han lanzado la consigna que sintetiza sus aspiraciones: "Otro mundo es posible”; c) De los socialdemócratas. La socialdemocracia internacional está planteando una agenda que pretende conciliar los intereses del capital con las demandas populares. Sin embargo, en los hechos, los gobiernos procedentes de esta adscripción doctrinaria están más bien plegados a la agenda política neoliberal. Un ejemplo es la denominada Tercera Vía propuesta por Giddens y aplicada por Tony Blair en Gran Bretaña, en consonancia con el gobierno demócrata estadounidense de de Bill Clinton. En esta perspectiva también abrevan planteamientos heterodoxos de corte neokeynesiano, institucionalista y desarrollista. El interés reside en salvar al sistema capitalista en su conjunto, así sea mediante la confección de una careta humana; 4) De los nacionalistas. El nacionalismo se plantea como una fuerza para el desarrollo ante los problemas generados por la globalización y la integración de bloques económicos regionales basados en el libre mercado. El Estado-nación ha sido utilizado, por la coalición neoliberal, como un instrumento político al servicio de la inversión extranjera y en detrimento de las posibilidades de desarrollo nacional. Bajo la postura de teóricos del neoestructuralismo y del nuevo desarrollismo se postula la idea de que el Estado puede asumir las funciones de un agente del desarrollo nacional, en una pauta alternativa al neoliberalismo; 5) De los poscapitalistas. Desde una vertiente radical se postula que el único posneoliberalismo susceptible es el que pretende construir una nueva sociedad que trascienda al capitalismo.

6. Poscapitalismo. La idea de poscapitalismo no necesariamente se reduce a la idea de socialismo o comunismo, y menos aún a su expresión como sistema de propiedad pública o estatal. Sin embargo, estas dos expresiones abarcan la mayor parte del ideal poscapitalista, pero no lo agotan. Históricamente, la idea de socialismo se ha instaurado como el proyecto alternativo de mayor envergadura frente al capitalismo. No obstante, en la práctica han ocurrido distintas experiencia que pueden o no colmar las expectativas de una nueva sociedad: el bloque comandado por la ex URSS, motejada como "socialismo realmente existente"; el caso de Cuba y el de China, que de ser un país comunista pasó a instaurar una vía altera dentro del capitalismo mundial. Otro caso lo ofrecen los países de Sudamérica gobernados por la izquierda y centro izquierda, que postulan un proyecto en vías de construcción denominado socialismo del siglo XXI, se trata de Venezuela, Bolivia y Ecuador, principalmente. Ante la irrupción severa de la crisis, varios analistas han replanteado la idea dependentista y marxista 
de que dentro del capitalismo no hay alternativa de desarrollo y que, por extensión, tampoco a ninguna de sus varias crisis, por lo que la salida real y duradera es una nueva sociedad fundada no en la maximización de ganancias sino en la necesidad de garantizar el complejo sistema de reproducción de la vida humana en el planeta con mejores condiciones materiales de vida y trabajo.

Tabla 4. Respuestas y salidas a la crisis

\begin{tabular}{|l|l|}
\hline \multicolumn{1}{|c|}{ Perspectiva } & \multicolumn{1}{c|}{ Descripción } \\
\hline Revolución tecnológica & $\begin{array}{l}\text { El salto cualitativo del capitalismo en las crisis es la inno- } \\
\text { vación tecnológica que inaugura una etapa de crecimiento }\end{array}$ \\
\hline Neoliberalismo regulado & $\begin{array}{l}\text { El neoliberalismo necesita contener las fuerzas especulati- } \\
\text { vas del mercado, principalmente financiero }\end{array}$ \\
\hline Posdesarrollo & $\begin{array}{l}\text { El mito del progreso y la modernidad requiere ser desman- } \\
\text { telado para dar paso a un retorno romántico a la comuni- } \\
\text { dad }\end{array}$ \\
\hline Desglobalización & $\begin{array}{l}\text { La globalización representa un proyecto impositivo que } \\
\text { requiere ser desmantelado en beneficio de un nuevo regio- } \\
\text { nalismo y nacionalismo desarrollista }\end{array}$ \\
\hline Posneoliberalismo & $\begin{array}{l}\text { Trascender el neoliberalismo significa abandonar la idea } \\
\text { del mercado como agente del desarrollo y el cálculo racio- } \\
\text { nal de utilidad como su sustrato }\end{array}$ \\
\hline Poscapitalismo & $\begin{array}{l}\text { Crear una nueva organización social más allá del mercado } \\
\text { y del móvil de la ganancia }\end{array}$ \\
\hline
\end{tabular}

\section{Conclusión}

La dinámica del capitalismo neoliberal representa una vorágine destructora de capital, población, naturaleza, infraestructura, cultura y conocimiento. Su objetivo primordial es maximizar las ganancias de los grandes capitales transnacionales, para lo cual promueve la estrategia del mercado total, la explotación de fuerza de trabajo barata, la depredación ambiental, la financiarización de la economía y la militarización de las relaciones internacionales. La insustentabilidad de la mayoría de la población se expresa en desempleo y subempleo, migración forzada, pobreza, hambre y muerte. La crisis general del sistema capitalista mundial no sólo expresa una crisis del sistema financiero conectada a una crisis de sobreproducción, sino que representa una crisis del modelo civilizatorio que, más allá de mostrar diversos rostros truculentos, pone en predicamento la vida humana en distintos ámbitos del planeta y anuncia una fractura en el proceso de metabolismo social humanidad-naturaleza. No se trata de cargar con tintes 
apocalípticos el análisis de nuestra compleja realidad mundial, sino que la intención es advertir la encrucijada epocal que nos plantea la crisis civilizatoria: o seguimos consecuentando los intereses del capital con toda su avalancha depredadora o planteamos alternativas sociales para garantizar la reproducción de la vida. La disyuntiva no es despreciable si tomamos en cuenta que la fractura metabólica impone desafíos inéditos al desarrollo del capitalismo en términos de los peligros que afronta la reproducción social y las condiciones biológicas para la producción.

El capitalismo en general y su configuración neoliberal en particular representan un modelo de civilización a todas luces insostenible. El inexorable proceso de concentración de capital, poder y riqueza en pocas manos, el modelo de acumulación centralizado y la innovación tecnológica basada en los países centrales han consolidado un sistema de civilización que profundiza el desarrollo desigual, por lo que no reviste validez universal ni es garante de la existencia humana. Ese modelo civilizatorio le confiere al capital una enorme capacidad de dominación que va más allá de la subsunción del trabajo directo, ahora abarca el control material de las condiciones generales de producción y reproducción social, es decir, los recursos naturales, el medio biótico y abiótico, las tecnologías, el entorno ecológico, las pautas culturales, la generación y aplicación de conocimiento, los patrones de consumo, las estructuras de pensamiento y los principios del sentido común. Este modelo descansa en una distribución desigual del conocimiento científico-tecnológico, el intercambio ecológico desigual, la transferencia de excedente, la superexplotación del trabajo inmediato, la devastación del medio ambiente, la privatización de los recursos naturales, la militarización de las relaciones internacionales y la precarización de la vida humana.

La acumulación capitalista centralizada es un proceso que paralelamente al crecimiento económico, impulsa un proceso destructivo que afecta las fuentes mismas de la producción de toda riqueza: el ser humano y la naturaleza. El parámetro único de tasa de ganancia activa una máquina de destrucción, con el agravante de que la desvalorización del trabajo, y con ello el deterioro de las condiciones de vida y trabajo de la mayoría de la población se convierte, bajo el neoliberalismo, en condición sine qua non para acrecentar los márgenes de ganancia, lo que le permite al capital generar ahorros incluso en materia de innovación tecnológica, pero no por mucho tiempo. Las corporaciones capitalistas están orilladas a maximizar sus ganancias como condición se supervivencia, por lo que no escatiman recursos para participar en esta escalada de destrucción.

Bajo este modelo civilizatorio basado en la "destrucción creativa”, la vida humana se convierte en un recurso desechable, que se puede destruir en aras de alcanzar los mayores beneficios posibles para el capital, al final de cuentas existe una vasta reserva laboral de trabajadores en el mundo que pueden suplir a los desechados. En el plano laboral, se implementan modelos de gestión laboral que conducen a la explotación extenuante del trabajo inmediato, lo cual incluye la disminución salarial, la inseguridad 
laboral, la mayor intensidad, incluso la extensión de la jornada laboral; también las políticas de subcontratación y las políticas de flexibilización y precarización laboral. Las formas de explotación laboral se han diversificado, no sólo se trata del asalariado, sino también del informal, infantil, femenil, entre otras. Se trata de un ataque sistemático y permanente en contra de los trabajadores y sus familias, lo que obra en condiciones de exclusión económica como productores, trabajadores y consumidores. Esto redunda en un deterioro dramático en sus condiciones de vida y trabajo. Otro capítulo nefasto de la destrucción, en este caso abrupta, de la vida humana es la violencia estatal, las guerras de conquista, que con el objetivo de apropiarse de recursos naturales estratégicos, como el petróleo y el agua, se destruyen vidas, infraestructuras, sociedades. En suma, para subsistir, este modelo civilizatorio se ve compelido a destruir capitales, empleos, infraestructuras, culturas, poblaciones. Sólo un nuevo sistema civilizatorio, basado en otros principios societales, detendrá esta loca y frenética carrera de destrucción compulsiva.

La respuesta pragmática a la crisis que en los hechos se está imponiendo, encabezada por el Estado, se orienta por la necesidad de rescatar al sector financiero y las grandes corporaciones que incurrieron en las prácticas especulativas. Bajo esta operación, se encubre las pérdidas, fraudes y especulaciones del gran capital, mediante la canalización de ingentes recursos públicos, pero también mediante la transferencia de excedente social de los países periféricos hacia los centrales, como sucede con el trasvase de ganancias de las sucursales a las matrices de los grandes bancos privados. Por añadidura, se refuerza la ofensiva en contra de los trabajadores, mediante programas de despido o profundización de la precarización laboral. En tanto, los desposeídos, desempleados, migrantes y trabajadores precarizados no merecen mayor atención. En ese contexto, el llamado a contener la especulación voraz de los financistas mediante la regulación es un llamado moral para regularizar la dinámica de acumulación capitalista, pero no va al fondo de la crisis.

La respuesta crítica a la crisis debe de tomar en cuenta su carácter sistémico y la debacle civilizatoria que concita. En contraposición a la idea burguesa de poner en el centro las necesidades de valorización del capital, sin reparar en los sacrificios humanos y ambientales que esto representa, se plantea la necesidad de comenzar por desarticular los férreos controles del capital sobre el poder, la naturaleza, el dinero, el conocimiento, la información y, en general, la humanidad. Dicha proposición es de gran calado, y nos remite a la idea de cambiar de rumbo para construir un mundo donde quepamos todos, como proclaman los movimientos sociales alternativos. En esa inteligencia, emergen, cuando menos, cuatro criterios básicos para, más allá de las preocupaciones coyunturales de la crisis financiera, construir una alternativa de desarrollo crítico orientada a generar el bien común social: 1) colocar en el centro el objetivo de mejorar sustancial las condiciones materiales y subjetivas de la mayoría de la población. En primera instancia se trata de garantizar la producción y reproducción de la humanidad en simbiosis con el entorno planetario; 2) generar cambios estructura- 
les, políticos e institucionales que trastoquen el sistema de acumulación y poder organizado por la globalización neoliberal; 3) promover la configuración de un sujeto colectivo de la transformación social, puesto que el gran capital no tiene ante sí un agente colectivo que le dispute el comando de la estrategia de acumulación y uso del excedente social. Esto requiere construir el poder popular, impulsar la democracia formal combinada con la democracia directa y articular a sectores sociales diversos que compartan este cometido; y 4) como criterio estratégico de factibilidad, entendido como la posibilidad de realización concreta de un desarrollo alternativo crítico, se impone la necesidad de impulsar un proyecto en pauta posneoliberal. Entre sus tareas iniciales, se puede enunciar la reconstrucción del Estado, con la intervención de los movimientos sociales, de forma tal que se organice alrededor de un poder que "mande obedeciendo". Pero también promover la intervención del mercado según los requerimientos sociales. Además es menester recuperar la soberanía política de los países periféricos y subdesarrollados y la construcción de nuevas modalidades de integración regional bajo pautas de solidaridad, complementariedad y solidaridad.

No obstante, es importante tomar nota de que la crisis no ha significado, por sí sola, un descarrilamiento del modelo neoliberal, ni la fulminación de su fundamento teórico — la economía neoclásica y neoliberal—, ni siquiera a contenido las operaciones especulativas. Todo lo contrario, se refuerzan los mecanismos de poder, se le confiere el respaldo político al FMI, a la vez que el neoclacisismo neoliberal sigue siendo el pensamiento dominante en las universidades y centros de investigación, y los programas de ajuste estructural continúan influyendo en gobiernos de derecha, centro y centroizquierda, y los financistas siguen acumulando ganancias. No obstante, hay experiencias alentadoras en algunos países de América Latina que intentan construir una ruta alterna al neoliberalismo. 


\section{Notas}

${ }^{1}$ La actual crisis entraña una inevitable depuración de capitales sobrantes, lo que algunos han llamado "destrucción creativa”, que responde a la necesidad recurrente de abaratar capital constante. Además se apuntala la concentración de poder en el Estado imperial y sus socios de los países subdesarrollados, con la aquiescencia de los principales organismos internacionales, lo cual configura el nuevo imperialismo (Harvey, 2005) o imperialismo colectivo (Amin, 2005). Como resultante, se aglutina una inconmensurable masa de riqueza en manos de una delgada élite de la burguesía transnacional. Este camino significa acrecentar a un mismo tiempo las de por sí enormes desigualdades sociales en los países periféricos, pero también en los propios países centrales, y las asimetrías entre regiones centrales, periféricas y subdesarrolladas.

${ }^{2}$ El desarrollo desigual comporta un proceso histórico de polarización económica, social y política entre regiones, países y clases derivada de la dinámica de acumulación capitalista centralizada, la división del trabajo, la estructura de poder y la lucha de clases en distintos ámbitos espaciales y niveles jerárquicos. Como resultado acontece la expansión de las desigualdades sociales expresada por la concentración de capital, poder y riqueza en manos de una pequeña élite capitalista confrontada a un abundante proceso de despojo, explotación y pobreza que constriñe paulatinamente las condiciones de vida y trabajo de la mayoría de la población. A nivel del sistema capitalista mundial tiene verificativo una diferenciación sintomática entre países imperialistas, centrales o desarrollados y países periféricos, subdesarrollados o dependientes. 


\section{Bibliografía}

Amin, Samir (2005), Las luchas campesinas y obreras frente a los desafíos del siglo XXI, El viejo topo, Barcelona.

Arrighi, Giovanni (2007), Adam Smith en Pekín. Orígenes y fundamentos del siglo XXI, Akal, Madrid.

Bartra, A. (10 de marzo de 2009), "La gran crisis”, La Jornada.

Beinstein, Jorge (2009), "La crisis en la era senil del capitalismo. Esperando inútilmente el quinto Kondratiev”, en El viejo topo, núm. 253.

Bello, Walden (2008), “Todo lo que usted quería saber sobre el origen de esta crisis pero teme no entenderlo”, Focus on the Golobal South.

Ídem (2009), “¿Llegó la hora de poner fin a la globalización?”, en http:// www.sinpermiso.info/textos/index.php?id=2758.

Caputo, Orlando (2009), “La crisis actual de la economía mundial. Una nueva interpretación teórica e histórica”, ponencia presentada en XII Seminario Internacional Los partidos y una nueva sociedad, México, 19-21 de marzo de 2009.

Delgado Wise, Raúl y Humberto Márquez (2009), “Towards a New Theoretical Approach to Understanding the Relationship between Migration and Development” en Social Analysis, Special issue (en prensa).

Dierckxsens, Wim (2009a), "La Gran Depresión del siglo XXI inaugura la administración Obama”, Observatorio internacional de la crisis, en http:// www.observatoriodelacrisis.org/readarticle.php?article_id=65.

Ídem (2009b), “Crisis sistémica y depresión mundial: Las causas estructurales de la crisis financiera”, Observatorio internacional de la crisis, en www.observatoriocrisis.org.

FAO (2009), "El número de víctimas del hambre es mayor que nunca”, en http://www.fao.org/fileadmin/user_upload/newsroom/docs/ Press\%20release\%20june-es.pdf.

Foladori, Guillermo e Invernizzi, Noela (2005), "Nanotecnología: beneficios para todos o mayor desigualdad”, en Redes, vol. 11, núm. 21.

Foladori, Guillermo (2009), “Las nanotecnología en el contexto actual”, ponencia presentada en el foro Nanotecnología en México: oportunidades y retos de la actualidad, Zacatecas, México, 24 de septiembre.

Ghanta, Praveen (2009), “Is Peak Oil Real? A List of Countries Past Peak”, en http://www.theoildrum.com/node/5576. 
Harvey, David (2005), “El ‘nuevo’ imperialismo: acumulación por desposesión”, en Panitch, Leo y Colin Leys (eds.), El nuevo desafío imperial. Social Register 2004, CLACSO, Buenos Aires.

Hinkelammert, Franz y Henry Mora (2008), Hacia una economía para la vida. Preludio a una reconstrucción de la economía, Editorial Tecnológica de Costa Rica, Cartago.

Holtz-Giménez, Eric (2007), “Cinco mitos sobre agrocombustibles”, Le Monde Diplomatique, edición Cono Sur, núm. 96.

Jalife-Rahme, Alfredo (2007), Hacia la desglobalización, México: Jorale Editores.

Katz, Claudio (2009), “Codicia, regulación o capitalismo”, Herramienta, núm. 41.

Márquez, Humberto (2008), “México en vilo: desmantelamiento de la soberanía laboral y dependencia de las remesas", Papeles de población, vol. 14, núm. 58.

Ídem (2009a), “La gran crisis del capitalismo neoliberal”, Documentos de trabajo, Unidad Académica en Estudios del Desarrollo, UAZ.

Ídem (2009b), “Hacia la construcción de los estudios críticos del desarrollo”, Documentos de trabajo, Unidad Académica en Estudios del Desarrollo, UAZ.

Marx, Karl (1975), El capital. El Proceso de producción del capital. Tomo I, Vol. 2, Siglo XXI Editores, México.

Mora, Henry (2009), “¿Divergencia internacional o desarrollo desigual? Ensayo sobre los fundamentos del comercio internacional, la condición periférica y el subdesarrollo”, Revisa Aportes, núm. 1.

Petras, James (2005), "Seis mitos sobre los beneficios de la inversión extranjera”, Rebelión, en http://www.rebelion.org/noticias/2005/7/17492.pdf.

Ídem (2009), “Depresión mundial, guerras regionales y declive del imperio de EEUU”, Rebelión, en http://www.rebelion.org/noticia.php?id=83718.

Vasapollo, Luciano (2008), "La precariedad como paradigma de la reestructuración capitalista en la fase de la crisis estructural”, ponencia presentada en las XI Jornadas de Economía Crítica, Bilbao, 27-29 de marzo.

Veltmeyer, Henry (2009), “The Global Crisis and Latin America”, en Martijn Konings (ed.), Beyond the Subprime Headlines: Critical Perspectives on the Financial Crisis, Verso, Londres. 
Wallerstein, Immanuel (2005), La decadencia del poder estadounidense, Era, México.

Recibido: 16.10.2009

Aceptado: 05.05.2010 